\section{A Radar Echo from Lightning}

RADAR observations on rain clouds are being made at Cambridge, using a vertically directed beam with a half-width of $3^{\circ}$ to half-power, a peak power of $40 \mathrm{~kW}$. with a $1 \mu$ sec. pulse on a wave-length of $3 \cdot 2 \mathrm{~cm}$., and a range-amplitude display (' $A$-scope'). The same aerial is used both for transmitting and for receiving.

During a violent thunderstorm on July 6, 1950, an intense echo of duration about 2 msec. was observed at a height of $12,000 \mathrm{ft}$. This echo was sufficiently strong to saturate the $A$-scope, so that its intensity is known to have been at least $2 \times 10^{-6}$ watts. At the same instant, a strong positive field-change was recorded at the ground on a point discharge-current apparatus. Accordingly, the possibility that the echo might have originated from a lightning discharge was investigated and the following conclusions reached.

The dielectric discontinuity between the hot air in the interior of a lightning column and the surrounding air would at best give an echo intensity $10^{-10}$ of the observed intensity. Direct radiation from the discharge on a frequency of $10,000 \mathrm{Mc}$./s. seems most unlikely. However, the echo could have been produced by a cylindrical column of electrons, and, using a method due to Blackett and Lovell ${ }^{1}$, the electron concentration necessary to give an echo of the strength observed was computed as $5 \times 10^{13}$ electrons $/ \mathrm{cm}$. length. The damping produced by electron collisions with neutral atoms and positive ions was taken into account, and the assumptions were made that the column lay along a diameter of a horizontal cross-section of the beam and that the diameter of the discharge column was less than one wave-length. In fact, only a short length of the column may have lain perpendicular to the beam, so that the estimated electron concentration is a lower limit.

This note is prompted by a recent report ${ }^{2}$ on radar lightning echoes, where, however, no estimates are given of absolute echo intensities or of conditions in the discharge.

Cavendish Laboratory,

IAN C. BROWNE

University, Cambridge. Jan. 3.

${ }^{1}$ Blackett and Lovell, Proc, Roy. Soc., A, 177, 183 (1941). - Ligda, Myron G. H., Bull. Amer. Met. Soc., 31, 279 (1950).

\section{A New Gem Mineral}

IN November 1945, Count Taaffe, a Dublin gemmologist, asked us to identify a pale mauve faceted gem-stone in which, though ostensibly a spinel, he had detected small but distinct double refraction by direct observation under a binocular microscope.

The properties of the stone (which weighed 1.41 carats) were found to be: refractive indices $\omega=$ $1 \cdot 723, \varepsilon=1 \cdot 719$, uniaxial negative; density $3 \cdot 62$; hardness 8 on Mohs's scale. Apart from the birefringence, it will be seen that these properties are very close to those for spinel ; but an X-ray examination showed conclusively that the stone had hexagonal symmetry and belonged to a now mineral species. The unit cell dimensions are: $a, 5 \cdot 72$; c, $18.38 \mathrm{~A}$., and the space group is $D^{6}{ }_{6}=C 6_{3} 2$. A spectrograph of a small fragment showed the presence of magnesium, beryllium and aluminium.

Recently, one of us (C. J. P.) discovered a second specimen (weighing 0.87 carats) of the new mineral among a mixed parcel of coloured stones, during a routine test. This had very similar properties to the first, and its identity was further substantiated by X-ray examination. More accurate refractive index measurements were obtainable on this specimen, using an Abbe-Pulfrich refractometer, the indices being $\omega=1.7208, \varepsilon=1.7167$.

Thus far, only these two cut specimens are known, and the origin of the mineral must remain uncertain, though in each case the stones were accompanied by others which definitely came from Ceylon, and the first specimen was typically Ceylon-cut. This is probably the only instance where a new mineral has been first encountered as a cut gem-stone.

Count Taaffe kindly allowed the removal of a small portion of his stone for microchemical analysis. When this has been completed a fuller report will be sent to the Mineralogical Magazine.

$$
\begin{aligned}
& \text { B. W. ANderson } \\
& \text { C. J. PAYNE }
\end{aligned}
$$

Laboratory of the Diamond, Pearl, etc., Section of the London Chamber of Commerce, 55 Hatton Garden, E.C.1.

G. F. Ctaringauli

Department of Mineralogy,

British Museum (Natural History), London, S.W.7.

Nov. 15.

\section{Upper Limit of Frequency for Human Hearing}

EFFECTS similar to those reported by Pumphrey ${ }^{1}$ were demonstrated to us in December 1945 by Dr. Maass of Bremen ${ }^{2}$. According to Maass, boneconducted vibrations up to $50 \mathrm{kc} . / \mathrm{s}$. $(150 \mathrm{kc} . / \mathrm{s}$. or more in the young) can be heard by most people, including some subjects normally regarded as totally deaf at ordinary frequencies both to air-borne and to bone-conducted sound.

Contrary to Pumphrey's findings with a resonant crystal transducer and an oscillator of continuously variable frequency, Maass showed, with a magneto. striction transducer and a choice of several fixed frequencies between 30 and $60 \mathrm{kc} . / \mathrm{s}$., that the tones could be distinguished in pitch, sounding not unlike tones between 8 and $16 \mathrm{kc} . / \mathrm{s}$.

No systematic work had been done to investigate the possibility of ill effects from the vibrations.

J. H. Combridge

J. O. ACKroYD

Post Office Engineering Department, London, E.C.1.

Dec. 8.

1 Pumphrey, R. J., Nature, 166, 571 (1950).

${ }^{2}$ Combridge, J. H., and Ackroyd, J. O., B.I.o.s. Final Report No. 606 (1946).

If it is true that persons totally deaf in the range of normally audible sounds ( $30-16,000$ c.p.s.) can perceive sound by bone-conduction in the range 16,000 100,000 c.p.s., this is a fact of great importance both for the theory of hearing and for the design and construction of hearing-aids, particularly if perception is associated with any useful degree of frequency discrimination above $16 \mathrm{kc} / \mathrm{s}$.

I am sceptical about this report; first, because I am dubious about the assessment of total deafness; secondly, because, from my own observations, I am satisfied that frequency discrimination in the generally accepted sense (namely, monotonic relation of pitch 